\title{
ANALISIS PENDAPATAN PEMBUDIDAYA RUMPUT LAUT EUCHEUMA SPINOSUM DI DESA PULAU PADAELO KECAMATAN PULAU SEMBILAN
}

\section{Analysis of Income Of Seaweed Eucheuma Spinosum Farmers In Padaelo Island, Pulau Sembilan District}

\author{
Hasan Basri ${ }^{1}$, Suryawati Salam ${ }^{2}$, dan Sri Mulyani ${ }^{2}$ \\ ${ }^{1}$ Program Studi Budidaya Perairan Program Pascasarjana, Universitas Bosowa \\ ${ }^{2}$ Fakultas Pertanian, Universitas Bosowa Makassar \\ E-mail: hasanbasri@yahoo.com
}

Diterima 10 Maret 2019/ Dipublikasi 02 Mei 2019

\begin{abstract}
ABSTRAK
Perairan pulau Padaelo merupakan salah satu wilayah potensial untuk pengembangan budidaya rumput laut Eucheuma spinosum. Aspek teknis perairan mendukung untuk dilakukan usaha budidaya namun aspek analisis pendapatan juga diperlu dikaji. Tujuan penelitian ini adalah menganalisis pendapatan pembudidaya rumput laut diperairan Desa Pulau padaelo serta membandingkan antara pendapatan yang diperoleh dengan biaya yang dikeluarkan pada usaha budidaya rumput laut. Dilaksanakan pada bulan Januari sampai Maret 2016. Metode analisis dilakukan dengan menentukan pendapatan yang diperoleh dari hasil pengurangan dari total pendapatan dikurangi total pengeluaran. Sedangkan $\mathrm{R} / \mathrm{C}$ ratiao diperoleh dengan membagi total pendapatan dengan total pengeluaran. Hasil Penelitian menunjukkan bahwa rata-rata pendapatan pembudidaya rumput lau adalah Rp. 43.010.000 pertahun atau Rp. 6.144.286 persiklus. R/C ratio sebesar 2,049 atau dengan kata lain sangat layak untuk diteruskan.
\end{abstract}

Kata Kunci: Euchema spinosum, Pendapatan, Pembudidaya dan R/C Rasio

\begin{abstract}
Padaelo island is one of the potential areas for cultivation of seaweed Eucheuma spinosum. The technical aspect of the waters of support to do farming but also income analysis diperlu aspects studied. The purpose of this study was to analyze revenue seaweed cultivators waters padaelo Island Village and comparing the income obtained by the cost incurred in seaweed farming. Implemented in January to March 2016. The analysis method to determine the income obtained from the reduction of total revenues minus total expenses. While the $R / C$ ratiao is obtained by dividing total earnings by total spending. Research shows that the average income of farmers grass Lau is Rp. Or Rp 43.01 million per year. 6144286 persiklus. $R$ / C ratio of 2,049 or very worthy to be forwarded.
\end{abstract}

\section{Keywords: Euchema spinosum, Farmers, Revenue and R/C Ratio}

\section{PENDAHULUAN}

Rumput laut merupakan komoditas perikanan Indonesia yang diharapkan mampu meningkatkan perekonomian masyarakat dan menyerap tenaga kerja serta meningkatkan devisa negara. Demikian juga dengan produk olahannya, baik dalam bentuk bahan dasar (keraginan, agar, dan alginat) maupun dalam bentuk formulasi dari ketiga bahan dasar tersebut. Peluang pasar pengembangan usaha rumput laut sangat menjanjikan dengan tingginya permintaan pasar rumput laut baik berupa bahan baku maupun produk-produk hasil olahannya, baik dalam pasar di dalam negeri maupun pasar ekspor. Meningkatnya kebutuhan agar dan keragenan nasional maupun dunia untuk dijadikan makanan/ minuman, bahan penunjang industry kosmetik, cat, farmasi dan industri kimia lainnya mendorong akselerasi pengembangan rumput laut pada on farm dan off farm (hulu-hilir).

Pemanfaatan rumput laut secara meluas memberikan peluang besar dalam pengembangan usaha budidayanya termasuk kepada nelayan yang juga ada kecendrungan untuk melakukan budidaya rumput laut, karena budidaya rumput laut memiliki keunggulan dibandingkan dengan komoditas perikanan budidaya lainnya, antara lain: (1) Teknologi budidaya yang mudah dilakukan; (2) Waktu pemeliharaan yang relatif singkat; (3) Anggaran yang relatif sedikit; (4) Penyerapan tenaga kerja yang tinggi; (5) Peluang pasar/ nilai ekonomis yang tinggi; (6) Memiliki fungsi ekologis.

Sulawesi Selatan merupakan salah satu sentra produksi rumput laut di Indonesia dan mulai 
melakukan kegiatan budidaya pada tahun 1986. Hal tersebut di dukung oleh potensi Sulawesi selatan yang memiliki panjang pantai $1937 \mathrm{Km}$ dan antara lain terdapat potensi budidaya laut sebesar 250.000 Ha dan budidaya tambak 98,617 Ha.

Kabupaten Sinjai memiliki luas wilayah 819,96 kilometer $^{2}$ dengan panjang pantai 31 kilometer dan memiliki gugusan pulau yang dinamakan Kepulauan Sembilan, jumlah pulau pulau ini adalah 10 buah. Secara administrasi kabupaten sinjai terdiri dari 9 Kecamatan dan 76 Desa/ Kelurahan. 1 Kecamatan diantaranya merupakan Kecamatan kepulauan yaitu Kecamatan Pulau Sembilan.

Keunggulan-keunggulan budidaya rumput laut tersebut merupakan Indikator Positif dalam upaya pengembangan usaha budidaya dan dapat menarik perhatian bagi pembudidaya rumput laut di Kecamatan Pulau Sembilan khususnya Desa Pulau Padaelo sebagai mata pencaharian karena sangat mudah dilaksanakan dan sangat prospektif.

Penelitian ini bertujuan menganalisis pendapatatan pembudidaya rumput laut di Desa Pulau Padaelo Kecamatan Pulau Sembilan dan menganalisis perbandingan pendapatan yang diperoleh dengan biaya yang dikeluarkan pada usaha budidaya rumput laut.

\section{METODE PENELITIAN}

Penelitian dilaksanakan di Desa Pulau Padaelo Kecamatan Pulau Sembilan Kabupaten Sinjai. Data primer diperoleh dari observasi, wawancara, kuisioner, dan dokumentasi yang dilakukan dilapangan. Jumlah responden ditentukan $15 \%$ dari jumlah populasi yang ada yakni 20 responden yang merupakan pembudidaya rumput laut dan mewakili karakteristik pembudidaya. Data sekunder diperoleh dari Dinas Kelautan dan Perikanan Kabupaten Sinjai.

Metode analisis dilakukan dengan menentukan:

1. Analisis pendapatan yaitu analisis yang dilakukan untuk memperoleh usaha budidaya rumput laut dengan rumus yang dikemukakan oleh Soekartawi (2002) sebagai berikut:

$$
\pi=T R-T C
$$

$$
\begin{aligned}
\mathrm{TR} & =\mathrm{P} \cdot \mathrm{Q} \\
\mathrm{TC} & =\mathrm{TFC}+\mathrm{TVC} \\
\text { dimana: } & \\
\pi \quad= & \text { Pendapatan } \\
\mathrm{TR} & =\text { Total Revenue } \\
\mathrm{TC} & =\text { Total cost } \\
\mathrm{TFC} & =\text { Total Fixed Cost } \\
\mathrm{TVC} & =\text { Total Variabel Cost } \\
\mathrm{P} & =\text { Harga Produk Rumput Laut }(\mathrm{Rp} / \mathrm{Kg}) \\
\mathrm{Q} & =\text { Jumlah Produk rumput laut yang } \\
& \text { dihasilkan }(\mathrm{Kg})
\end{aligned}
$$

2. Analisis $\mathrm{R} / \mathrm{C}$ Rasio

Adapun rumus R/C Rasio ( Soekartawi,2002) yaitu :

$$
\mathrm{R} / \mathrm{C} \text { Rasio }=\frac{T R}{T C}
$$
dimana,

$\mathrm{TR}=$ Total Revenue $($ Penerimaan Total $)(\mathrm{Rp})$
$\mathrm{TC}=$ Total Cost (Biaya Total) $(\mathrm{Rp})$

dengan Ketentuan :

R/C Rasio > 1 maka Usaha memperoleh keuntungan

$\mathrm{R} / \mathrm{C}$ Rasio $=1$ maka usaha dalam keadaan impas

$\mathrm{R} / \mathrm{C}$ Rasio $<1$ maka usaha mengalami kerugian jika hasil perhitungan $\mathrm{R} / \mathrm{C}$ rasio lebih besar dari satu maka usaha budidaya rumput laut Euchema spinosum layak diusahakan, apabila hasil perhitungan R/C

\begin{tabular}{|c|c|c|c|c|c|c|}
\hline \multirow[t]{2}{*}{1} & \multicolumn{6}{|l|}{ Biaya Tetap } \\
\hline & 1. Perahu & unit & 1 & 5.000 .000 & 5.000 .000 & 5.000 .000 \\
\hline & 2. Pelampung utama & buah & 12 & 50.000 & 600.000 & 1.200 .000 \\
\hline & 3. Pelampung kecil & buah & 50 & 15.000 & 750.000 & 2.250 .000 \\
\hline & 4. Terpal Plastik & buah & 20 & 8.500 & 170.000 & 340.000 \\
\hline & 5. Linggis/jangkar & buah & 22 & 40.000 & 880.000 & 880.000 \\
\hline & 6. Tali jangkar No. 9 & $\mathrm{~kg}$ & 20 & 40.000 & 800.000 & 1.600 .000 \\
\hline & 7. Tali Utama No. 12 & $\mathrm{~kg}$ & 40 & 40.000 & 1.600 .000 & 3.200 .000 \\
\hline & 8. Tali No. 1 & $\mathrm{~kg}$ & 2 & 60.000 & 120.000 & 840.000 \\
\hline & 9. Tali No. 5 & $\mathrm{~kg}$ & 42 & 40.000 & 1.680 .000 & 5.040 .000 \\
\hline & 10. Bibit & $\mathrm{kg}$ & 1500 & 2.000 & 3.000 .000 & 3.000 .000 \\
\hline & \multicolumn{4}{|l|}{ Total biaya tetap } & 14.600 .000 & 23.350 .000 \\
\hline \multirow{5}{*}{ II } & 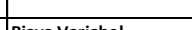 & & & & & \\
\hline & Biaya Variabel & & & & & \\
\hline & $\begin{array}{l}\text { 1. Biaya perawatan } \\
\text { 2. Upah tenaga kerja }\end{array}$ & \begin{tabular}{|l} 
minggu \\
orang
\end{tabular} & $\frac{7}{7}$ & $\begin{array}{l}135.000 \\
225.000\end{array}$ & $\begin{array}{r}945.000 \\
1.575 .000\end{array}$ & $\begin{array}{r}6.615 .000 \\
11.025 .000\end{array}$ \\
\hline & \multicolumn{4}{|l|}{ Total biaya variabel } & 2.520 .000 & 17.640 .000 \\
\hline & Total Biaya & & & & 17.120 .000 & 40.990 .000 \\
\hline \multirow{5}{*}{ IIII } & \begin{tabular}{|l|} 
Penerimaan \\
\end{tabular} & & & & & \\
\hline & Rumput laut kering & $\mathrm{kg}$ & 2400 & 5.000 & 12.000 .000 & 84.000 .000 \\
\hline & Total Penerimaan & & & & & 84.000 .000 \\
\hline & \begin{tabular}{|l} 
Pendapatan \\
\end{tabular} & & & & Pertahun & 43.010 .000 \\
\hline & & & & & Persiklus & 6.144 .286 \\
\hline
\end{tabular}
lebih kecil dari satu, maka usaha budidaya rumput laut Euchema spinosum tidak layak diusahakan : Jika hasil perhitungan $\mathrm{R} / \mathrm{C}$ rasio sama dengan satu maka usaha budidaya rumput laut Euchema spinosum impas.

\section{HASIL DAN PEMBAHASAN}

Hasil pengamatan rincian biaya pendapatan budidaya rumput laut di Kabupaten Sinjai dapat dilihat pda tabel beirkut.

Tabel 1. Rincian Biaya dan Pendapatan Budidaya

Rumput Laut Eucheuma spinosum di Desa Padaelo Kecamatan Pulau Sembilan Kabupaten Sinjai

Pendapatan dari hasil produksi budidaya rumput laut di perairan Desa Padaelo dalam satu siklus budidaya rata-rata $2.400 \mathrm{~kg}$ kering dengan harga jual Rp.5.000. Untuk satu siklus budidaya diperoleh pendapatan sebesar rata-rata Rp. 12.000.000,-. Dalam setahun pendapatan pembudidaya sebesar Rp. 84.000.000 untuk tujuh kali siklus, atau Rp. 6.144.286/siklus. Menurut Indriani dan Suminarsih (2003), Produksi rumput laut sangat dipengaruhi oleh laju pertumbuhan harian dan terhindar dari penyakit. Sedangkan Kordi (2010) menyatakan bahwa bibit 100 gr. Dapat dipanen setelah mencapai berat 600 gr.

Berdasarkan hasil analisis perbandingan pendapatan dengan biaya (R/C Rasio) pada budidaya rumput laut di Desa Padaelo didapatkan hasil 2,049. Hal ini menunjukkan bahwa $\mathrm{R} / \mathrm{C}$ rasio>1 sehingga dapat diinterpretasikan bahwa usaha budidaya menguntungkan. Salah satu indikator kelangsungan usaha budidaya adalah mendatangkan keuntungan bagi pembudidaya atas modal investasi yang dikeluarkan sehingga dapat dikatakan bahwa usaha tersebut layak. Analisis usaha perlu dilakukan untuk mengetahui besar modal yang akan digunakan untuk 
memulai usaha budidaya dan seberapa jauh keuntungan yang akan dicapai dalam usaha tersebut.

\section{KESIMPULAN}

Hasil penelitian dapat disimpulkan bahwa bahwa rata-rata pendapatan pembudidaya rumput lau adalah Rp. 43.010.000 pertahun atau Rp. 6.144.286 persiklus. R/C ratio sebesar 2,049 atau dengan kata lain sangat layak untuk diteruskan.

\section{DAFTAR PUSTAKA}

Anto Dajan, 1996. Pengantar Metode Statistik Jilid II, Jakarta : LP3S.

Anonim. 2005. Profil Rumput Laut Indonesia. Direktorat Jenderal Perikanan Budidaya Departemen Kelautan dan Perikanan. Jakarta

Anggadiredja Jana., T, A. Zatnika., H. Purwoto dan S. Istini. 2011. Rumput Laut Pembudidayaan, Pengolahan, dan Pemasaran Komoditas Perikanan Potensial. Penebar Swadaya. Jakarta.

Aslan,L.M. 1995 Seri Budidaya Rumput Laut, Kanisisus. Yogyakarta

Asaad, A.1.J. 2008. Analisis Usaha Budidaya Rumput Laut sistem long line. Balai Riset Perikanan Budidaya Air Payau. Maros

Ask, E.1 dan R.V.Azanza. 2002. Advances in cultivation technology of commercial Euheumatoid species : a review with suqqestions for future research Aquaculture 206: 257-277

Budi, S., \& Zainuddin, Z. (2012). Peningkatan Asam Lemakrotifer Brachionus Plicatilis Dengan Periode Pengkayaan Bakteri Bacillus Sp. Berbeda. Octopus: Jurnal Ilmu Perikanan, 1(1), 15.

Budi, S., Karim, M. Y., Trijuno, D. D., Nessa, M. N., Gunarto, G., \& Herlinah, H. (2016). The use of fatty acid omega-3 HUFA and Ecdyson Hormone To Improve Of Larval Stage Indeks and Survival Rate Of Mud Crab Scylla olivacea. Simposium Nasional Kelautan dan Perikanan, 3, 487-498.

Budi, S., Karim, M. Y., Trijuno, D. D., Nessa, M. N., Gunarto, G., \& Herlinah, H. (2016, August). Tingkat Dan Penyebab Mortalitas Larva Kepiting Bakau, Scylla spp. Di unit Pembenihan Kepiting Marana Kabupaten Maros. In Prosiding Forum Inovasi Teknologi Akuakultur (Vol. 1, No. 1, pp. 465-471).

Budi, S., Karim, M. Y., Trijuno, D. D., Nessa, M. N., \& Herlinah, H. (2018). Pengaruh Hormon Ecdyson Terhadap Sintasan Dan Periode Moulting Pada Larva Kepiting Bakau Scylla olivacea. Jurnal Riset Akuakultur, 12(4), 335-39.

Kordi, M dan H. Ghufran. 2010. A to Z Budidaya Biota Akuatik untuk Pangan, Kosmetik, dan Obat-Obatan. Andi Offset, Yogyakarta.

Kordi, M dan H. Ghufran 2011. Kiat Sukses Budidaya Rumput Laut di Laut dan Tambak. Andi. Yogjakarta.
Mc Hugh, D.J and B.V Lanier 1983. The Worl Seaweed Industry and Trade, South China Sea Fisheries Development and Coordinating. Programme Food Agri Culture Organization of the United Nation, Manila

Panawa, Y. 2013. Pertumbuhan Rumput Laut dalam Hubungannya dengan Suhu dan Salinitas. Skripsi Fakultas Ilmu Alam dan Teknologi Rekayasa Universitas Halmahera. Tobelo

Parenrengi, A., E. Suryati dan Rahmansyah, 2011. Budidaya Rumput Laut. Badan Penelitian dan Pengembangan Kelautan dan Perikanan Kementrian Kelautan dan Perikanan Republik Indonesia, Djakarta

Retraubun, A.S.W. 2004. Pulau-Pulau Kecil Di Indonesia. Departemen Kelautan dan Perikanan. Direktorat Jenderal Pesisir dan Pulau-pulau Kecil. Djakarta

Winarno F.G. 1990. Teknologi Pengolahan Rumput Laut. Pustaka Sinar. Jakarta. 